\title{
Acknowledgments to Associate Editors
}

The Editor-in-Chief wishes to thank the following Associate Editors, who have donated their time and expertise to assist in selecting the novel and high-quality articles among the 64 submissions the Transactions of JSASS receives in 2016.

Editor-in-Chief Kimiya KoMURASAKI

\begin{abstract}
Associate Editors
Aerodynamics, Aircraft Design, Rotorcraft field

Jinsoo CHO, Professor, School of Mechanical Engineering, Hanyang University, Korea (2014-)

Song FU, Professor, School of Aerospace Engineering, Tsinghua University, China (2014-)

Shinkyu JeOng, Professor, Department of Mechanical Engineering, Kyunghee University, Korea (2016-)

Naofumi OHNISHI, Professor, Department of Aerospace Engineering, Tohoku University, Japan (2014-)

Shigeru SAITO, Senior Adviser, Chief Engineering Office, JAXA, Japan (2014-)

Keisuke SAWADA, Professor, Department of Aerospace Engineering, Tohoku University, Japan (2014-)

Nobuyuki TsubOI, Professor, Faculty of Engineering, Kyushu Institute of Technology, Japan (2014-)
\end{abstract}

Structures and Materials field

Ken Higuchi, Professor, Department of Aerospace Engineering, Muroran Institute of Technology, Japan (2015-)

Chyanbin HwU, Professor, Department of Aeronautics and Astronautics, National Cheng Kung University, Taiwan (2014-)

Yasuyuki MiYazAKI, Professor, Department of Aerospace Engineering, Nihon University, Japan (2014-)

Toshio Ogasawara, Professor, Division of Advanced Mechanical Systems Engineering, Tokyo University of Agriculture and Technology, Japan (2016-)

Flight Dynamics, Avionics \& Systems, Air Traffic Management field

Mark A. BRown, Chief Researcher, Air Traffic Management Department, Electronic Navigation Research Institute, Japan (2014-)

Keumjin LEE, Associate Professor, Department of Air Transportation and Logistics, Korea Aerospace University, Korea (2016-)

Yoshimasa OCHI, Professor, Department of Aerospace Engineering, National Defense Academy, Japan (2014-)

Roberto SABATINI, Professor, School of Engineering, RMIT University, Australia (2015-)

Masayuki SATO, Associate Senior Researcher, JAXA, Japan (2016-)

Shinji SuzuKI, Professor, Department of Aeronautics and Astronautics, The University of Tokyo, Japan (2014-)

Hiroyuki TAKAnO, Associate Professor, Aerospace Engineering, National Defense Academy, Japan (2014-)

Astrodynamics, Space System, Space Utilization field

Matthew Phillip CARTMELl, Professor, Aerospace Centre of Excellence, Department of Mechanical and Aerospace Engineering, University of Strathclyde, UK (2016-)

Jun'ichiro KAwAGUCHI, Senior Fellow, ISAS, JAXA, Japan (2014-)

Takashi KIDA, Professor Emeritus, Mechanical Engineering, University of Electro-Communications, Japan (2014-)

Saburo MAtunAgA, Professor, Department of Mechanical and Aerospace Engineering, Tokyo Institute of Technology, Japan (2014-)

Colin R. MCINNES, James Watt Chair, Professor, School of Engineering, University of Glasgow, UK (2014-)

Daniel J. ScheERES, Distinguished Professor and A. Richard Seebass Endowed Chair, Aerospace Engineering

Sciences, University of Colorado, USA (2014-)

Katsuhiko YAMADA, Professor, Mechanical Engineering, Osaka University, Japan (2014-)

Jing-rui ZHANG, Professor, School of Aerospace Engineering, Beijing Institute of Technology, China (2015-)

Aerospace Propulsion field

James R. HulKA, Engineering Specialist, Jacobs Engineering, NASA Marshall Space Flight Center, USA (2014-)

In-Seuck Jeung, Professor, Aerospace Engineering, Seoul National University, Korea (2014-)

Masahiro KurosAKI, Advisor, Research and Development, Cell Tech Inc., Japan (2014-)

Yasushi OHKAWA, Associate Senior Researcher, JAXA, Japan (2014-)

Toru ShIMADA, Professor, Department of Space Flight Systems, ISAS, JAXA, Japan (2015-)

Toshinori Watanabe, Professor, Aeronautics and Astronautics, The University of Tokyo, Japan (2015-) 